\title{
Rectosigmoid Neoplasm
}

National Cancer Institute

\section{Source}

National Cancer Institute. Rectosigmoid Neoplasm. NCI Thesaurus. Code C4877.

A benign or malignant neoplasm that affects the rectosigmoid region. Representative examples of benign neoplasms include lipoma and leiomyoma. Representative examples of malignant neoplasms include carcinoma, lymphoma, and sarcoma. Rectosigmoid adenomas always exhibit epithelial dysplasia and are considered premalignant neoplasms. 